\title{
China's scientific footprint in the global HIV/AIDS research: Productivity, impact and collaboration
}

\author{
Ping Liu ${ }^{1}$, Xiangming $\mathrm{Mu}^{2}$, $\mathrm{HaO} \mathrm{Xie}^{3}$ \\ ${ }^{1}$ School of Information Management, Wuhan University, \\ Wuhan, 430072, CHINA \\ ${ }^{2}$ School of Information Studies, \\ University of Wisconsin-Milwaukee, Milwaukee WI, 53102, USA \\ ${ }^{3}$ School of Chemistry, Chemical Engineering and Life Science, \\ Wuhan University of Technology, Wuhan, 430070, CHINA \\ e-mail: h.xie@whut.edu.cn (corresponding author)
}

\begin{abstract}
HIV/AIDS is the leading cause of death by infectious diseases in China, a country with the largest population in the world. China has made great efforts and progress in studying, treating, and controlling HIV/AIDS in the past 15 years. This situation calls the need for systematic analysis of the status and capability of China in the global HIV/AIDS research. It will facilitate the world to integrate and utilize resources from China in fighting against the disease. A bibliometric analysis in HIV/AIDS research of China was conducted for the period 2000-2014. HIV/AIDS articles and citations were measured as research productivity. A set of indices were examined to explore China's scientific footprint in the global HIV/AIDS research. China has exhibited higher-than-average research performance since 2008. Two stages of HIV/AIDS research development have been identified as in 2000-2005 and 2005-2014. Major HIV/AIDS research institutions and scientists in China have been detected. Co-citation analysis of publications revealed important publications that acted as intellectual turning points of China's HIV/AIDS research evolution during 2000-2014. Co-occurring keywords analysis revealed important and center terms of HIV/AIDS research publications from China. Combinations of related issues show that the HIV/AIDS research is currently focused on the "epidemiology of HIV/AIDS in China" and "molecular mechanisms of HIV/AIDS infection".
\end{abstract}

Keywords: Bibliometrics; Research performance; Scientific productivity; HIV/AIDS research; China 
Liu, P. , Mu, X. \& Xie, H.

\section{INTRODUCTION}

China, with a population over 1.3 billion, is constantly facing challenges from infectious diseases. HIV/AIDS has been reported in China since early 1980s and now is the leading cause of death by infectious diseases in China (China Health and Family Planning Statistics Yearbook 2014). By the end of 2013, it was reported that there were 437,000 people living with HIV/AIDS and 136,000 deaths around the country (China AIDS Response Progress Report 2014). China initiated HIV-prevention activities in early stages of the epidemic and committed to prevention efforts. Significant achievements have been made in developing public awareness and education campaigns to address HIV prevention, treatment, care, and research in China. In the new millennium, the development of economic, science and technology promotes academic institutions in China to conduct more epidemiological and operational research in HIV/AIDS. Understanding the research status and capability of China will facilitate the world to integrate and utilize resources of China in fighting against HIV/AIDS.

Research performance of research bodies such as countries, institutions and individuals is generally represented by publications, patents, awards and funding. Lacking of standards makes it difficult to compare patents, awards and funding between different research bodies. Therefore, journal publication (especially peer reviewed articles) has been widely accepted as a good and unique index for evaluating research performance. By means of bibliometric approaches, major research performance dimensions including research productivity, quality, impact, and collaboration are measured based on quantitative analysis of journal publications and citations.

The present study aims to employ bibliometric approaches to portray China's HIV/AIDS research and development profile. Special attention was paid to explore productivity, impact and collaboration of China's HIV/AIDS research.

\section{LITERATURE REVIEW}

HIV/AIDS is one of the hottest topics attracting scientists in a broad range of disciplines. The rapid growth of literature calls the need for systematic monitoring and evaluation of HIV/AIDS research. Bibliometrics has a long tradition in quantitative assessments of HIV/AIDS research in different regions and countries. A survey of the MEDLINE file showed that by the end of 1987 (that is, five years after the Centers for Disease Control first adopted the name "acquired immunodeficiency syndrome"), 54 countries produced AIDS publications in 25 languages and in 1,170 different journals (Self, Filardo and Lancaster 1989). Ramos et al. (2005) found that countries with a greater estimated number of individuals living with HIV are not leading the scientific production on HIV/AIDS. Falagas et al. (2006) found that regions included in the low and medium human development index categories showed a higher proportion of increase in research productivity than the developed countries. 
Africa is the most infected area in the world (http://aidsinfo.unaids.org/). Several scientists investigated and evaluated HIV/AIDS research about or from African countries (Macias-Chapula and Mijangos-Nolasco 2002; Onyancha 2008; Uthman 2008; 2010). They revealed that African countries have made significant achievement in the number of publications and collaborations in HIV/AIDS literature. Total expenditure on health, private expenditure on health, and adult literacy rate may be important factors to affect HIV/AIDS research output in Africa. It is essential for African scientists to establish multiple collaborations beyond historical, political, and cultural lines to share knowledge and expertise on HIV/AIDS. The assessment of HIV/AIDS research in the Latin American and Caribbean regions showed that USA, Haiti, and Canada were the main productive countries of HIV/AIDS research in this region (Macias-Chapula, Rodea-Castro and Narvaez-Berthelemot 1998; Macias-Chapula 2000). Main aspects of HIV/AIDS papers focused on epidemiology, complications, and trends issues. Uusküla et al. (2015) recently assessed the HIV/AIDS research productivity in 27 European Union (EU) countries and the structural level factors associated with levels of HIV/AIDS research productivity. They found that HIV/AIDS research productivity varies noticeably across EU countries, and this variation is associated with recognizable structural factors. In Asia, Patra and Chand (2007) analyzed Indian AIDS research based on bibliographic data. They found that there was a rapid growth of HIV/AIDS literature from 1992 onwards. Relative productivity of India is still low and requires more focused research and development. In summary, these studies provided detailed descriptions of the global HIV/AIDS research performance.

In the new millennium, China is rising as an emerging scientific power. China's research performance in many areas has been extensively assessed. For example, Liu et al. (2015) investigated China's global growth in social science research and indicated that China's publications in the Social Science Citation Index (SSCl) database have been rising in terms of volume, world share, and global ranking. Fu et al. (2015) analyzed malaria research in China and found that Chinese studies on malaria mainly focus on the epidemiology and biomedical fields. Huang et al. (2015) used bibliometric analysis to probe into the evolution of China's science and technology policies and the roles of core government agencies in policy-making. Wang et al. (2015) analyzed microcystins research in China and worldwide. They found that China made article publications at a faster rate than the worldwide average rate and the focus of China on microcystin research was different to other countries. Wang and Li (2014) presented bibliometric analysis of literature from China on animal-derived regenerative implantable medical devices. They predicted the research trends and provided an informed basis of decision making for researchers and clinicians. In summary, these studies provided detailed information of recent China's research performance.

Although China's research performance and global HIV/AIDS research performance have been extensively investigated, factors related to variation in HIV/AIDS literatures of China have not been examined. The present study aims to fill some of the gap in existing research and provide insights into HIV/AIDS research in China from 2000 to 2014. 


\section{RESEARCH OBJECTIVE}

The objective of this research is to investigate and gauge China's performance and position in global HIV/AIDS research during 2000-2014. More specifically, the following issues will be addressed:

(a) Major achievements of China's HIV/AIDS research including research output, impact and collaboration profile during 2000-2014.

(b) Main characteristics of China's HIV/AIDS research such as development stages, research bodies and core journals during 2000-2014.

(c) Evolution footprint and intellectual structure of China's HIV/AIDS research during 2000-2014.

\section{MATERIALS AND METHOD}

Bibliometrics takes advantages of mathematical and statistical methods to analyze scientific publications. It adopts quantitative performance indicators to get over the disadvantage of subjectivity in peer review and expert judgments, and has been used to assess research performance in an increasing amount and variety of studies (Rinia et al. 1998; Van Raan 2004). In the present study, the bibliographic data were retrieved from the Web of Science $^{\mathrm{TM}}$ Core Collection (http://thomsonreuters.com/web-of-science-core-collection) until Dec 31, 2014. During the last 15 years (2000-2014), the database has collected nearly 200,000 records of articles on the topic "HIV" or "human immunodeficiency virus" or "acquired immunodeficiency syndrome" (Here the abbreviation "AIDS" is not considered as the topic term since it cannot be clearly distinguished from the word "aids"). Over 70 percent of these records are for articles. Nearly 80 percent was published by top ten productive countries (USA, England, France, Italy, South Africa, Canada, Germany, Spain, China, and Australia). Therefore, article records and citations of these ten countries were selected and retrieved as the benchmark references.

Five indices, Annual Growth Rate and doubling time of research publications and citations, Activity Index, and Attractive Index, were calculated to evaluate the performance of China and other productive countries in HIV/AIDS research (Anson et al. 2010; Bornmann and Mutz 2015; Chen and Guan 2011). The Annual Growth Rate $\left(A G R_{i}^{n}\right)$ of publications and citations for the ith country from the $t$ th year to the $(t+n)$ th year is defined with Formula 1 . The doubling time $\left(D T_{i}^{n}\right)$ of publications and citations for the ith country from the th year to the $(t+n)$ th year is defined with Formula 2. For comparing a country's recital with that of the world performance, the Activity Index $\left(A I_{i}^{t}\right)$ for the ith country in the th year during the given period is defined with Formula 3 . For characterizing the relative impact of a country's research output in a subject field as reflected by the citations they received during the period, the Attractive Index $\left(A A I_{i}^{t}\right)$ for the ith country in the th year during the given period is defined with Formula 4. 


$$
\begin{array}{ll}
A G R_{i}^{n}=\sqrt[n]{\frac{C_{i}^{t+n}}{C_{i}^{t}}}-1 & \text { (Formula 1) } \\
D T_{i}^{n}=\frac{\log _{10} 2}{S L S_{i}^{t+n}} & \text { (Formula 2) } \\
A I_{i}^{t}=\frac{\left(P_{i}^{t} / \sum P\right)}{\left(T P^{t} / \Sigma T P\right)} & \text { (Formula 3) } \\
A A I_{i}^{t}=\frac{\left(C_{i}^{t} / \Sigma C\right)}{\left(T C^{t} / \Sigma T C\right)} & \text { (Formula 4) }
\end{array}
$$

$C_{i}^{t}$ is the HIV/AIDS-citation of the ith country in the $t$ th year; $C_{i}^{t+n}$ is the HIV/AIDS citation of the ith country in the $t$ th year and $(t+n)$ th year; $S L S_{i}^{t+n}$ is the slope of the linear fitting based on the HIV/AIDS publications or citations of the ith country from the $t$ th year to the $(t+n)$ th year on the 10-base logarithmic scale; $P_{i}^{t}$ is the HIV/AIDS-publications of the $i$ th country in the th year; $\sum P$ is the HIV/AIDS-publications of the ith country during the given publication period; $T P^{t}$ is the total HIV/AIDS-publications of the ten countries in the $t$ th year; $\sum T P$ is the total HIV/AIDS-publications of the ten countries during the given publication period; $\sum C$ is the HIV/AIDS-citations of the ith country during the given publication period; $T C^{t}$ is the total HIV/AIDS-citations of the ten countries in the th year; $\sum T C$ is the total HIV/AIDS-citations of the ten countries during the given publication period.

To gain insight of the HIV/AIDS research development, the software CiteSpace II (Chen 2004, 2006; Chen, Ibekwe-SanJuan and Hou. 2010) was used to produce the co-occurrence network of keywords and references to map and detect the intellectual structure as well as the evolution footprints of intellectual turning points of HIV/AIDS publications of China.

\section{RESULTS AND DISCUSSION}

\section{Overall Performance of China's HIV/AIDS Research}

A total number of 113,615 articles have been published by top ten productive countries from 2000 to 2014. These articles have been cited 2,416,941 times. China contributed 6,462 articles that have been cited 76,181 citations. Figure 1 presents sustained remarkable increases of article publications (Panel A) and citation frequencies (Panel B) of China during 2000-2014. It not only means that China become more productive in this area, but also indicates that HIV/AIDS research science impact of China becomes stronger and stronger. In the ten year window 2004-2013, it was observed exponential growth of articles and citations of most countries (Figure S1, see supplementary materials). Based on the semi logarithmic presentation of the publications and citation frequencies, the annual growth rate of publications and citations was calculated (Table 1 ). The growing speed of citations is higher than that of publications for both the average of ten countries and individual productive countries, which to some degree indicates that the HIV/AIDS research is 
increasingly attractive. China and South Africa exhibited significant higher annual growth rate and shorter doubling time, indicating HIV/AIDS research of both countries is growing faster than other eight countries.

(A) Sum of articles and article fraction

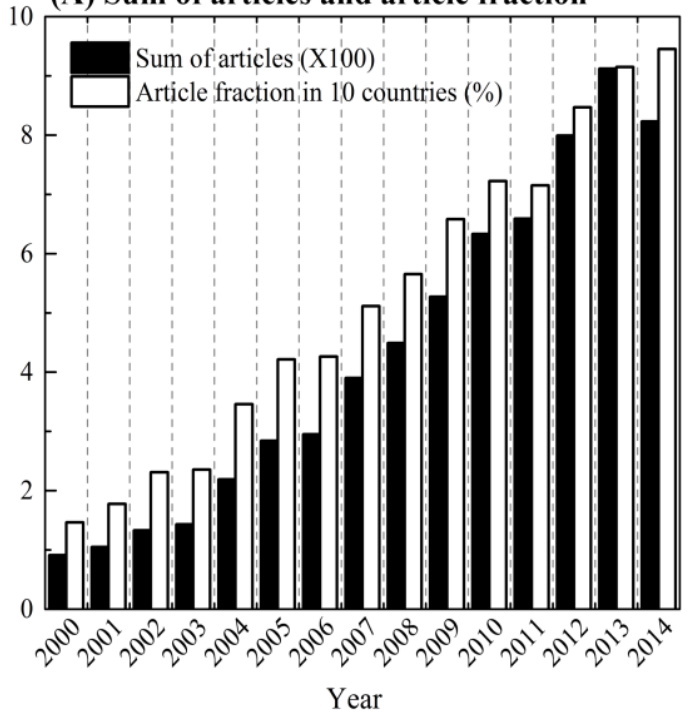

(B) Sum of citations and citation fraction

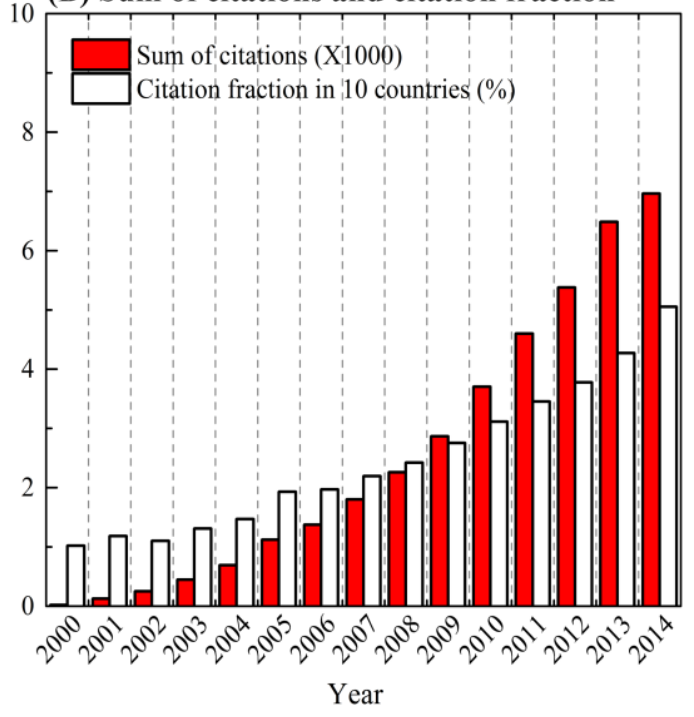

Figure 1: Cumulative Number of Articles and Citations of China During 2000-2014.

Table 1: Productivity and Growth Rates of Article Publications and Citations of the Ten Countries.

\begin{tabular}{|c|c|c|c|c|c|c|}
\hline & \multicolumn{2}{|c|}{$\begin{array}{l}\text { Publication Productivity } \\
(2000-2014)\end{array}$} & \multicolumn{2}{|c|}{$\begin{array}{c}\text { Article growth } \\
(2004-2013)\end{array}$} & \multicolumn{2}{|c|}{$\begin{array}{l}\text { Citation growth } \\
\text { (2004-2013) }\end{array}$} \\
\hline & Articles & Citations & $\mathrm{DT}^{*} / \mathrm{R}^{2}$ & AGR* & $\mathrm{DT}^{*} / \mathrm{R}^{2}$ & AGR* \\
\hline 10 countries & 113,615 & $2,416,941$ & $13.8 / 0.985$ & 5.2 & 5.4 / 0.972 & 13.9 \\
\hline USA & 69,535 & $1,701,185$ & $14.3 / 0.975$ & 5.0 & $5.3 / 0.973$ & 14.1 \\
\hline England & 12,441 & 328,535 & 12.0 / 0.961 & 5.7 & 4.9 / 0.972 & 15.1 \\
\hline France & 9,719 & 232,217 & $-\quad / 0.572$ & 1.2 & 6.4 / 0.956 & 11.6 \\
\hline S Africa & 7,200 & 125,762 & $3.8 / 0.926$ & 19.8 & 2.4 / 0.981 & 33.9 \\
\hline Canada & 6,837 & 154,301 & $8.1 / 0.938$ & 8.7 & 4.4 / 0.984 & 16.9 \\
\hline Italy & 6,632 & 139,584 & $-\quad / 0.339$ & 1.3 & 6.7 / 0.972 & 11.8 \\
\hline China & 6,462 & 76,181 & $4.4 / 0.986$ & 17.2 & $2.9 / 0.986$ & 28.2 \\
\hline Germany & 6,081 & 146,426 & $-\quad / 0.685$ & 4.5 & $5.3 / 0.983$ & 13.9 \\
\hline Spain & 5,625 & 108,557 & $-\quad / 0.851$ & 4.5 & $5.2 / 0.971$ & 14.1 \\
\hline Australia & 4,519 & 103,851 & $7.2 / 0.905$ & 11.2 & $4.0 / 0.976$ & 18.9 \\
\hline
\end{tabular}

*Note: AGR, annual growth rate in percent; DT, doubling time in year.

Although the size of research institutions in a country may have an impact on its research output, there is no significant connection between the research institution numbers and the research productivity of a country in HIV/AIDS research (Table S2, see supplementary materials). China has the second most number of research institutions. However, the average institutional article publication of China is the lowest in the ten countries. In contrast to China, South Africa has the least number of research institutions and the highest average institutional publication. This implies that only a small portion of China's research institutions are interested in HIV/AIDS. In other countries especially in South Africa, 
a relative large portion of the research institutions put their focus on HIV/AIDS research. Therefore, China still has a great potential in developing HIV/AIDS research if more China's research institutions are involved in studying this disease.

The Activity Index (Al) is considered as a relative performance indictor for characterizing the research effort of a country to a given field. Higher Al value means the country makes more research effort than other countries. Comparing with other countries, South Africa and China elevated dramatically from the bottom position to the top position (Figure 2, Panel A). The turning point was at 2008 when both countries changed their positions not only relatively to other countries and but also to the average level. Attractive Index (AAI) is used to characterize the relative impact of a country's publications in a specific field as reflected by the citations they attract in this study. Higher value of AAI means the relative citation impact of the country is higher than other countries. Comparing with other countries, South Africa and China raised their positions dramatically from the bottom level to the top level (Figure 2, Panel B). The turning point is at 2010 when both countries changed their positions not only relatively to other countries and but also to the average level. The AAl and Al changes demonstrate that China and South Africa gradually put more efforts in HIV/AIDS research and received more attentions.

To determine "cost-effectiveness", i.e., whether the effort devoted to a research field (the publication effort) has sufficient return in terms of its impact (citations), a relational chart (Figure 2, Panel C) was built to present the relative performance situation determined together by Al and AAl scores among countries (Chen and Guan 2011; Schubert and Braun 1986). The citation per year of a publication generally reaches the highest point in the second year (Qiu and Chen 2009), which is also demonstrated in the present study by the fact that the AAI turning point is two years after the Al turning point (Figure 2, Panels $A$ and $B)$. Therefore, AAI scores with two years lag were related to Al scores for constructing the AAI/AI relationship. The relational chart was a two-dimensional orthogonal diagrams and the "main diagonal" (the red dash line) represents the "balanced" situation. In the present study, the relative position of all points to the main diagonal (red dash line) shows that efforts and returns of the ten countries were in "balanced" situation during the period. The significant position change of two points "China (2012)" and "S Africa (2012)" relative to "China (2000)" and "S Africa (2000)" clearly described the great improvement of both countries from 2000 to 2014 . The improvement was displayed by the remarkable position changes from points "China (2000-2007)" and "S Africa (2000-2007)" to "China (2008-2012)" and "S Africa (2008-2012)".

China and South Africa were similar in most of the HIV/AIDS research performance. Since collaboration was associated with the enhancement of research (Frenken, Holzl and de Vor 2005), the international collaboration was analyzed for the two countries (Figure 2, Panel D). The data showed that 63 percent of articles and 80 percent of citations by South Africa were with international coauthors. While for China, only 41 percent of articles and 57 percent of citations were with international contributions. There were 141 countries had coauthored articles with South Africa, and only 119 countries with China. Therefore, 
although international collaboration was important to both countries, more promotions and research impact in HIV/AIDS research had been made by South Africa through international collaboration. These results support earlier research that collaborative authorship affects citation flow (Lancho Barrantes et al. 2012).

(A) Activity Index (AI) of 10 countries

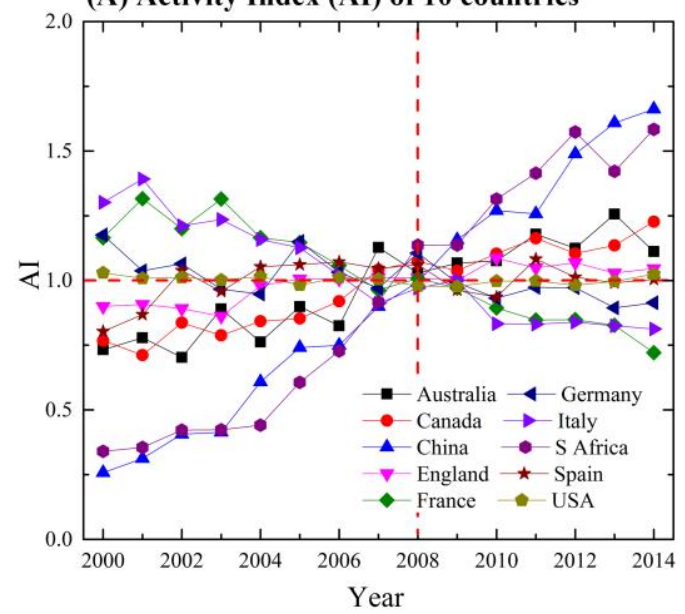

(C) AI vs. AAI

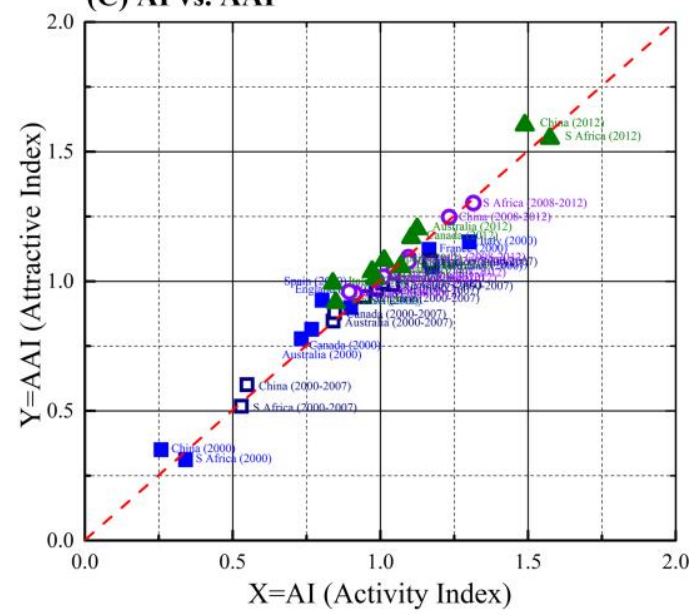

(B) Attractive Index (AAI) of 10 countries

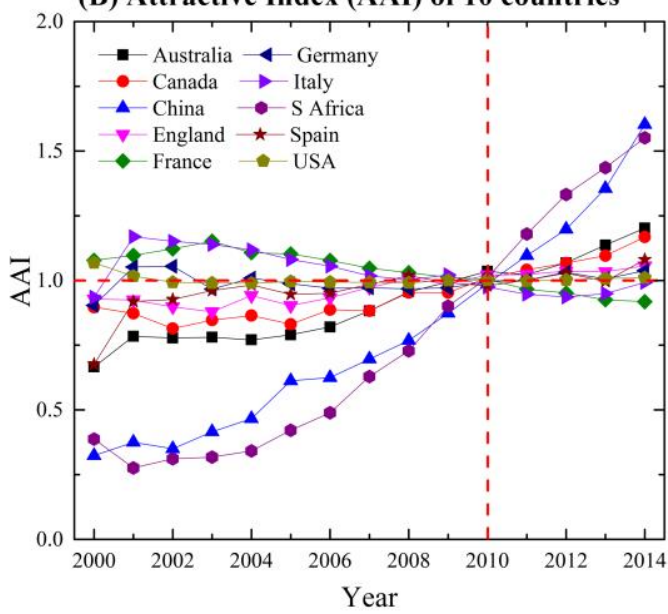

(D) International HIV/AIDS research publications of China and South Africa

\begin{tabular}{|c|c|c|}
\hline $\begin{array}{l}\text { Research performance } \\
\text { during 2000-2014 }\end{array}$ & China & South Africa \\
\hline \multicolumn{3}{|l|}{ Total publications } \\
\hline Articles (Citation frequency) & $6462(76181)$ & $7200(125762)$ \\
\hline \multicolumn{3}{|c|}{ Publications w ith out internation al coauthor(s) } \\
\hline Articles (Citation frequency) & $3805(32583)$ & $2644(25262)$ \\
\hline Collaborative countries & 119 countries & 141 countries \\
\hline Top five countries with most & USA (1858) & USA (2703) \\
\hline coauthor ed publications & Japan (187) & England (1438) \\
\hline \multirow[t]{3}{*}{ (coauthored articles) } & England (180) & Switzerland (339) \\
\hline & Canada (167) & Canada (338) \\
\hline & Australia (166) & Netherlands (286) \\
\hline
\end{tabular}

Figure 2: AAl, Al, and Relational Chart displaying Al vs. AAI of Ten Countries. (Note: For a colored illustration of this figure, the reader is referred to the web version of the article.)

\section{Analysis of HIV/AIDS Publications from China}

The HIV/AIDS publication records including articles, letters, proceedings papers, and reviews from China were further analyzed to gain insight of HIV/AIDS research in China. From 2000 to 2014, China has published over 7,000 HIV/AIDS research publications that have been cited for nearly 87,000 times. Panel A of Figure 3 illustrates growth trends of China's HIV/AIDS publications and citations. Two stages of publication development with different growth rates were observed in the semi logarithmic presentation of publication growth (the black dash line for 2000-2005 and the green dash line for 2005-2014) and citation growth (the red dash line for 2000-2005 and the blue dash line for 2005-2014), implying the exponential growth of publications and citations during these periods. The 
decrease of the slope from the black dash line to that of the green dash line indicates that the exponential growth of publications in the time window 2000-2005 was faster than in 2005-2014. Similarly, faster exponential growth of citations was observed in 2000-2005 than in 2005-2014.

During 2000-2014, top ten productive Chinese institutions accounted for 48.4 percent of the papers published and 53.4 percent of citations (Figure 3, Panel B). Chinese Academy of Sciences was the most productive organization in HIV/AIDS research. It has published 951 papers (13.5 percent of the total papers) that have been cited 13,278 times (15.3 percent of total citations). The two institutions in Hong Kong (Chinese University of Hong Kong and University of Hong Kong) exhibited higher $\mathrm{H}$-indices than most institutions in Mainland China, indicating a higher level of HIV/AIDS research quality in Hong Kong. The author with the most publications and the highest cumulative citation frequency is Professor Ng TB from the Chinese University of Hong Kong. He has published 210 HIV/AIDS papers that have been cited 4,910 times. Panel $C$ of Figure 4 presents the top ten prolific authors who accounted for 15.0 percent of the total publications and 17.1 percent of total citations.

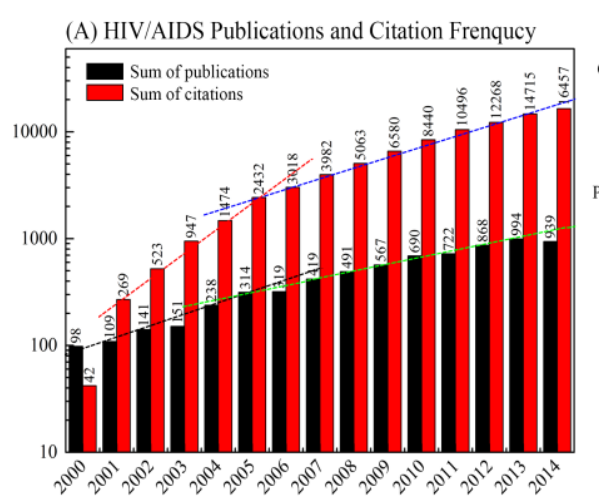

(C) Top 10 Prolific Authors in China

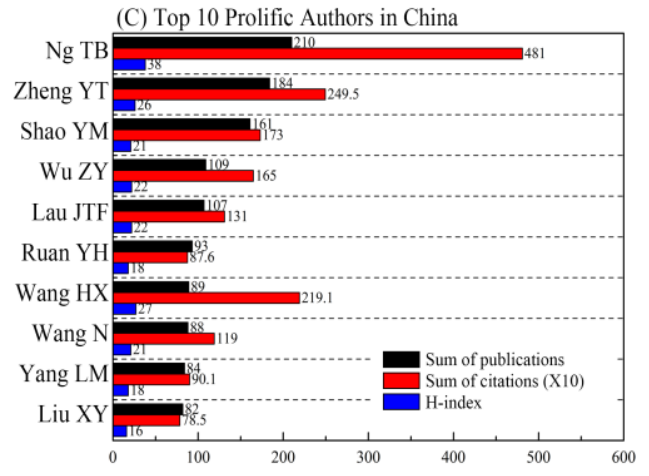

(B) Top 10 Productive Institutions in China

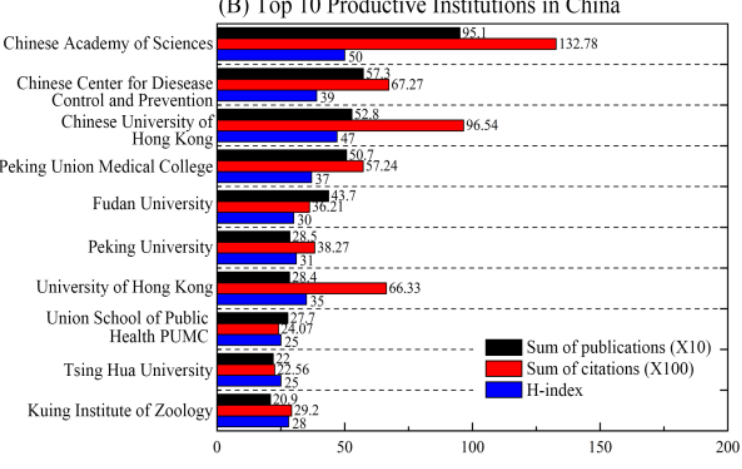

(D) Distributions by zone of journals and papers

\begin{tabular}{ccccccc}
\hline \multirow{2}{*}{ Zone } & \multicolumn{2}{c}{ No. of journals } & & \multicolumn{2}{c}{ No. of papers } \\
\cline { 2 - 3 } \cline { 5 - 6 } Zone 1 & 31 & 2.3 & & 2353 & 33.3 \\
\hline Zone 2 & 163 & 12.2 & & 2350 & 33.3 \\
\hline Zone 3 & 1138 & 85.4 & & 2357 & 33.4 \\
\hline
\end{tabular}

Figure 3: Growth of HIV/AIDS research in China (Panel A) and Top Contributing Institutions (Panel B), Top Prolific Authors (Panel C), and Distributions by Zone of Journals (Panel D). (Note: For a colored illustration of this figure, the reader is referred to the web version of the article.) 
HIV/AIDS publications of China occurred in 1,332 journals during 2000-2014. 11 journals published over five HIV/AIDS papers yearly by Chinese researchers. As per the Bradford Law (Bradford 1934), the journals are grouped into three zones producing similar number of articles (Figure 3, Panel D). 31 core journals are grouped in zone 1 published 2,366 papers accounting for one third of the total output (Table S1, see supplementary materials). Similarly, the second zone comprises of 163 journals and 1,138 journals are grouped in third zone. Accordingly the relations of the zone are $31: 163: 1138$ that confirms the implementation of Bradford's Law.

\section{Evolution Footprint and Intellectual Structure of HIV/AIDS Research in China}

To present the evolution footprint and intellectual structure of HIV/AIDS research in China, the software CiteSpace II (Chen 2004, 2006; Chen, Ibekwe-SanJuan and Hou 2010) was employed to construct co-occurrence networks of keywords and citations of the Chinese HIV/AIDS publications (Figure 4). Three issues were addressed including identifying the nature of research fronts, labeling specialties and detecting emerging trends and abrupt changes in a timely manner. In the visualization of the network, the node size represented the overall frequency of occurrence of citations or keywords and the colored rings of the nodes represented yearly time-slices. A trail of several pink rimmed nodes (those with a high measure of "betweenness centrality") highlighted the transition and evolution between different clusters (and relating topics). A burst of citations or keywords (nodes with the center being highlighted in red) provided evidence that a particular publication was associated with a surge of citations or keywords. Lines that connected nodes were co-citation or co-occurring keyword links with the colors of these lines to show when a connection was made for the first time. The information of 25 cited references with the highest scores of betweenness centrality in Panels A and B of Figure 4 are given in Table S3 (see supplementary materials).

Panel A of Figure 4 shows the co-citation network based on highly cited papers by Chinese researchers during 2000-2014. The JIANG-1993, an article of HIV-1 inhibition by a peptide, had a highest betweenness centrality and played a central role in the intellectual base for the HIV/AIDS research in China. CHAN-1997, WU-2007, and some articles followed it and formed the intellectual turns in the HIV/AIDS-research. The CHAN-1997 mainly examined the core structure of gp41 from the HIV envelope glycoprotein. The largest citation tree-ring of WU-2007 indicated significant citations to it during this period. The top three largest clusters drawn by CiteSpace II were illustrated with dashed circles to show the HIV/AIDS research front in China. Focuses of these clusters were "antipathogenic protein and peptides" (Cluster \#1), "epidemiology of HIV/AIDS in China" (Cluster \#2), and "molecular mechanism of HIV infection" (Cluster \#3). The Cluster \#1 existed as an isolated cluster and represented an active research filed around 2007 since the color of patches between nodes inside the cluster were almost green (2007). The intellectual basis for the Clusters \#2 and \#3 were provided by articles WU-2007 (Cluster \#2) and CHAN-1997" (Cluster \#3) as determined by their unique positions in the structure of these clusters. These salient intellectual turning points usually acted as structural holes (Burt 2009) by which the nodes in one cluster networks were connected with those in another cluster 
networks. The intellectual turning points linking different clusters were essential to understand how specialties and different thematic trends during different periods interact with each other in the long-range development path. Here, CHAN-1997 and WU-2007 played such bridging roles in the HIV/AIDS research development evaluation in China during 2000-2014. In terms of specific connection structures, JIANG-1993 was a transitional pivot node which links blue network patches (2000), green network patches (2007), and an orange network patch (2013). The green patches were links to the nodes including the pivot node CHAN-1997 in the Cluster \#3. The orange patch was connected to the pivot node WU-2007 in the Cluster \#2 through a set of nodes and links. Therefore, the two clusters were bridged by the three pivot nodes. With the highest centrality score, the bridging connection role of JIANG-1993 in the merged co-citation network was most significant.

In order to present a dynamic evolution footprint of the HIV/AIDS research intellectual bases and fronts, a time-zone visualization graph, which emphasizes the temporal relationships, was generated by CiteSpace II (Figure 4, Panel D). The dynamic time-slicing paragraph of key references standing for research intellectual bases and fronts made it is easy to track the evolution path of HIV/AIDS research in China over 2000-2014. Clearly, the time-zone visualization graph firstly showed that the earlier publications, e.g., JIANG-1993, CHAN-1997, and JIANG-1999, obtained multi-period citations, and presented stable intellectual bases for the long-term development of HIV/AIDS research in China. No significant citation burst over 2001-2006. Subsequently, three intellectual turning points, WU-2007, CHOI-2007, RUAN-2007 become research fronts, and provide intellectual bases for the follow-up researches. Then, LU-2008, ZHANG-2009, and LIAO-2010 play stronger connecting roles during the whole 15-year period and present intellectual bases for the latest HIV/AIDS research in China. In sum, the time-zone view conveys a picture of the visual footprint of HIV/AIDS research fronts and intellectual bases in China over 2000-2014.

To gain insight of HIV/AIDS research in China, the co-occurring keyword networks were constructed among keywords with high frequency in HIV/AIDS publications (Figure 4, Panel C). Keywords such as "infection", "human-immunodeficiency-virus", "china", and "hiv-1" with large font size are frequently mentioned by Chinese HIV/AIDS researchers. In order to find fast growing topics of HIV/AIDS research, co-occurring keywords were detected for their bursting scores (Kleinberg 2003). The top 30 keywords with the highest bursting score and time were illustrated in Panel D of Figure 4. The keywords "pisum-sativum", "seeds", and "purifications" with the strongest bursts appeared in 2000-2005 and were referred to the topic "purification and analysis of antiviral agents from a plant" (and were related to the Cluster \#1 as shown in Panel A of Figure 4). Three keywords "meta-analysis", "syphilis", and "cohort" appearing in 2012-2014 showed the latest growing topic in HIV/AIDS research, which were represented by the researches such as RUAN-1997 in Cluster \#1 as shown in Panel A of Figure 4. 
(A) Co-citation reference network

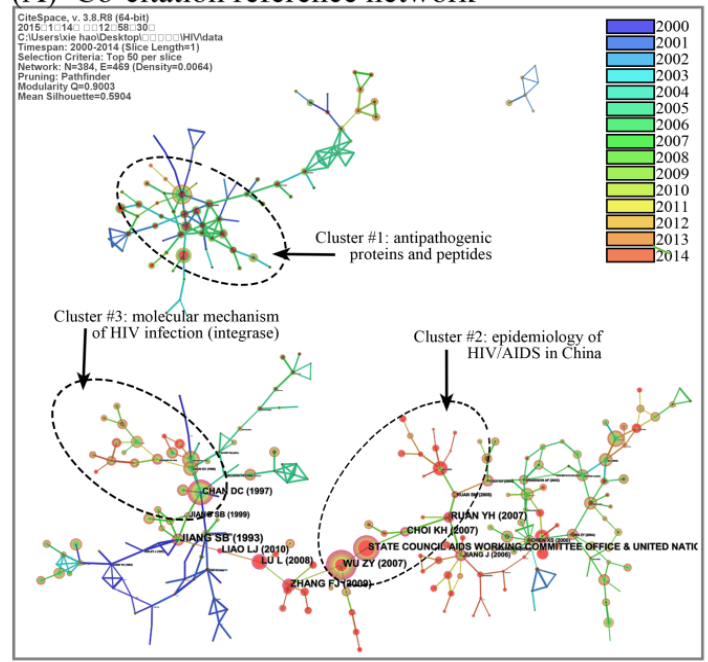

(C) Co-occurring keyword network

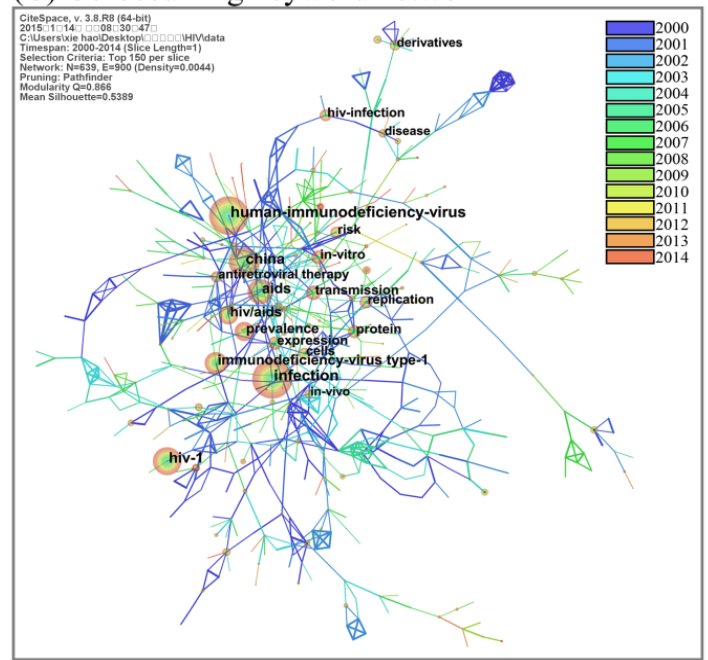

(B) Time-zone view of co-cited references

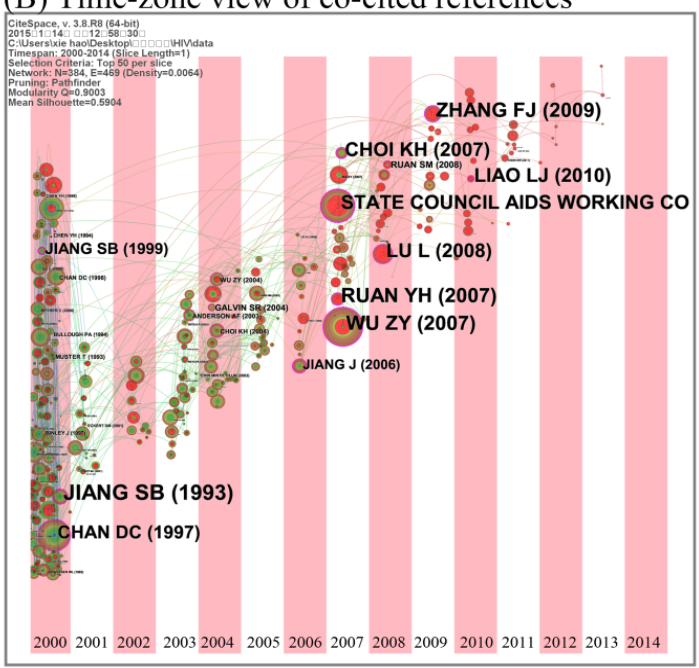

(D) Co-occurring keywords with strongest bursts

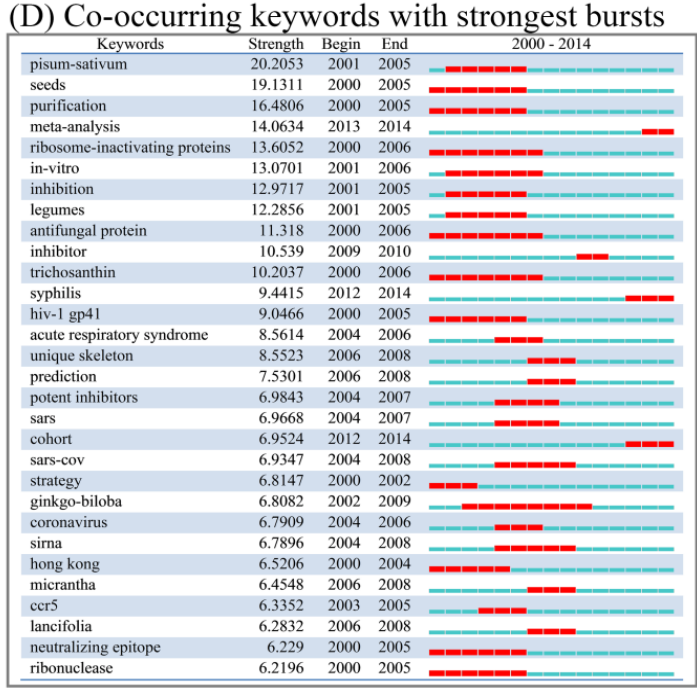

Figure 4: Co-Citation Reference Networks (Panel A) and the Time-Zone View of Co-Cited References (Panel B) in HIV/AIDS Publications from China. Co-Occurring Keyword Network

(Panel C) and 30 Co-Occurring Keyword with Strongest Bursts (Panel D). (Note: For a colored illustration of this figure, the reader is referred to the web version of the article.)

\section{CONCLUSION}

In this study, a coherent comprehensive scientometric evaluation framework was employed to investigate China's scientific footprint in the global HIV/AIDS research during 2000-2014. Analysis of research productivity and impact revealed higher-than-average research performance of China in the global HIV/AIDS research. However, China still has a great potential in HIV/AIDS research if more China's institutions are involved in studying this disease. Encouraging collaborations between China and foreign countries in HIV/AIDS research will facilitate the world to take advantages of resources from China in fighting against the disease and improve China's impact on HIV/AIDS research. Analysis of major characteristics of China's HIV/AIDS research (i.e., stages of research development, top productive research institutions, top prolific scientists, and core journals of China's 
HIV/AIDS research) is not only helpful for governments and funding bodies to make policies and provide financial supports in public health, but also useful for research bodies in setting up research directions and strategies. Top research institutions and scientists will have good opportunities in obtaining grants based on their previous excellence in the HIV/AIDS research. Other institutions and researchers will have to think about their research competence and expertise in contributing to future HIV/AIDS research. This can be based on the hot topics and research trends in HIV/AIDS, as indicated by important publications and center terms detecting by means of co-citations analysis and co-occurring keywords analysis. In the present study, combinations of related issues show that the HIV/AIDS research of China is currently focused on the "epidemiology of HIV/AIDS in China" and "molecular mechanisms of HIV/AIDS infection".

\section{ACKNOWLEDGEMENT}

This research is supported by the National Natural Science Foundation of China (71203164, 71573196) and the Fundamental Research Funds for the Central Universities of China.

\section{REFERENCES}

Anson, M.J. P., Fabozzi, F.J., and Jones, F.J. 2010. The handbook of traditional and alternative investment vehicles: investment characteristics and strategies. Hoboken: John Wiley \& Sons, Inc.

Bradford, S.C. 1934. Sources of information on specific subjects. 1934. Engineering, Vol. 137: 85-86.

Burt, R.S. 2009. Structural holes: The social structure of competition. Harvard University Press.

Bornmann, L., and Mutz, R. 2015. Growth rates of modern science: a bibliometric analysis based on the number of publications and cited references. Journal of the Association for Information Science and Technology, Vol. 66, no. 11: 2215-2222.

Chen, C. 2004. Searching for intellectual turning points: Progressive knowledge domain visualization. Proceedings of the National Academy of Sciences of the United States of America, Vol. 101(Suppl.): 5303-5310.

Chen, C. 2006. CiteSpace II: detecting and visualizing emerging trends and transient patterns in scientific literature, Journal of the American Society for Information Science and Technology, Vol. 57, no. 3: 359-377.

Chen, C., Ibekwe-SanJuan, F., and Hou, J. 2010. The structure and dynamics of co-citation clusters: a multiple-perspective co-citation analysis. Journal of the American Society for Information Science and Technology, Vol. 61, no. 7: 1386-1409.

Chen, K. and Guan, J. 2011. A bibliometric investigation of research performance in emerging nanobiopharmaceuticals. Journal of Informetrics, Vol 5, no. 2: 233-247.

China Health and Family Planning Statistics Yearbook 2014. Beijing: Peking Union Medical College Press. (in Chinese)

China AIDS Response Progress Report. 2014. Available at: http://www.unaids.org/ 
sites/default/files/documents/CHN_narrative_report_2014.pdf.

Falagas, M.E., Bliziotis, I.A., Kondilis, B. and Soteriades, E.S. 2006. Eighteen years of research on AIDS: contribution of and collaborations between different world regions. AIDS Research and Human Retroviruses, Vol. 22, no. 12:1199-1205.

Frenken, K., Holzl, W. and de Vor, F. 2005. The citation impact of research collaborations: the case of European biotechnology and applied microbiology (1988-2002). Journal of Engineering and Technology Management, Vol. 22, no. 1-2: 9-30.

Fu, H., Hu, T., Wang, J.Y., Feng, D., Fang, H.Q., Wang, M.L., Tang, S.F., Yuan, F. and Feng, Z.C., 2015. A bibliometric analysis of malaria research in China during 2004-2014. Malaria Journal, Vol. 14: 195

Huang, C., Su, J., Xie, X., Ye, X.T., Li, Z., Porter, A. and Li, J.A. 2015. A bibliometric study of China's science and technology policies: 1949-2010. Scientometrics, Vol. 102, no. 2: 1521-1539.

Kleinberg, J. 2003. Bursty and hierarchical structure in streams. Data Mining and Knowledge Discovery, Vol. 7, no. 4: 373-397.

Lancho Barrantes, B. S., Guerrero Bote, V. P., Rodríguez, Z. C. and de Moya Anegón, F. 2012. Citation flows in the zones of influence of scientific collaborations. Journal of the American Society for Information Science and Technology, Vol. 63, no. 3: 481-489.

Liu, W.S., Hu, G.Y., Tang, L. and Wang, Y.D. 2015. China's global growth in social science research: Uncovering evidence from bibliometric analyses of $\mathrm{SSCl}$ publications (1978-2013). Journal of Informetrics, Vol. 9, no. 3: 555-569.

Macias-Chapula, C.A. 2000. AIDS in Haiti: A bibliometric analysis. Bulletin of the Medical Library Association. Vo. 88, no. 1: 56-61.

Macias-Chapula, C.A., and Mijangos-Nolasco, A. 2002. Bibliometric analysis of AIDS literature in Central Africa. Scientometrics, Vol. 54, No. 2: 309-317.

Macias-Chapula, C.A., Rodea-Castro, I.P. and Narvaez-Berthelemot, N. 1998. Bibliometric analysis of AIDS literature in Latin America and the Caribbean. Scientometrics, Vol. 41, no. 1-2: 41-49.

Onyancha, O. B. 2008. Growth, productivity, and scientific impact of sources* of HIV/AIDS research information, with a focus on eastern and southern Africa. African Journal of AIDS Research, Vol. 7, no. 1: 55-70.

Patra, S.K. and Chand, P. 2007. HIV/AIDS research in India: A bibliometric study. Library \& Information Science Research, Vol. 29: 124-134.

Qiu, H. and Chen, Y.F. 2009. Bibliometric analysis of biological invasions research during the period of 1991 to 2007. Scientometrics, Vol. 81, no. 3: 601-610.

Rinia, E.J., van Leeuwen, T.N., van Vuren, H.G. and van Raanb, A.F.J. 1998. Comparative analysis of a set of bibliometric indicators and central peer review criteria: evaluation of condensed matter physics in the Netherlands. Research Policy, Vol. 27, no. 1: 95-107.

Ramos, J.M., Gutierrez, F., Padilla, S., Masia, M. and Martin-Hidalgo, A. 2005. Geography of medical publications: an overview of HIV/AIDS research in 2003. AIDS, Vol. 19, no. 2: 219-220.

Schubert, A. and Braun, T. 1986. Relative indicators and relational charts for comparative assessment of publication output and citation impact. Scientometrics, Vol. 9, no. 5/6: 
281-291.

Self, P., Filardo, W. and Lancaster, F.W. 1989. Acquired immunodeficiency syndrome (AIDS) and the epidemic growth of its literature. Scientometrics, Vol. 17, no. 1-2: 49-60.

Uthman, O.A. 2008. HIV/AIDS in Nigeria: a bibliometric analysis. BMC Infectious Diseases. Vol. 8: 19.

Uthman, O.A. 2010. Pattern and determinants of HIV research productivity in sub-Saharan Africa: bibliometric analysis of 1981 to 2009 PubMed papers. BMC Infectious Diseases, Vol. 10: 47.

Uusküla, A., Toompere, K., Laisaar, K.T., Rosenthal, M., Pürjer, M.L., Knellwolf, A., Läärä, E., and Des Jarlais, D.C. 2015. HIV research productivity and structural factors associated with HIV research output in European Union countries: a bibliometric analysis. BMJ Open Vol 5: e006591.

Van Raan, A.F.J. 2004. Measuring science. capita selecta of current main issues. In: Moed HF, Glänzel W, Schmoch U, eds. Handbook of quantitative science and technology research. Dordrecht: Kluwer Academic Publishers.

Wang, H.M. and Li, F.Y. 2014. Bibliometric analysis of the literature from the mainland of China on animal-derived regenerative implantable medical devices. Frontiers of Materials Science, Vol. 8, no. 4: 403-408.

Wang, Y., Hou, S.W., Ke, F. and Gao, H. 2015. Bibliometric analysis of research on microcystins in China and worldwide from 1991 to 2011. Deslination and Water Treatment, Vol. 53, no. 1: 272-283. 


\section{China's Scientific Footprint in the Global HIV/AIDS Research:}

\section{Productivity, Impact and Collaboration}

Ping Liu, Xiangming Mu, Hao Xie

\section{Supplementary materials}
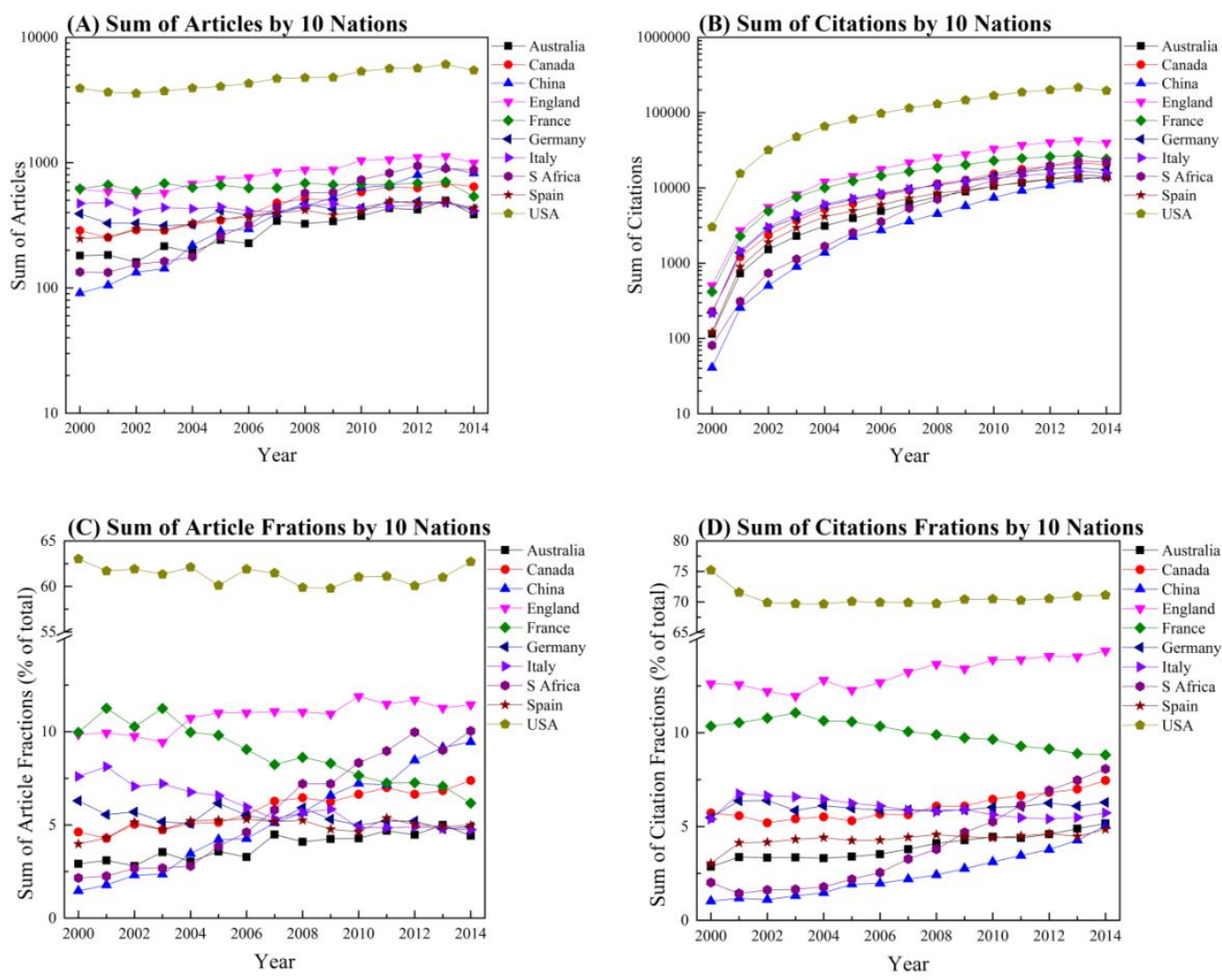

Figure S1: Cumulative number of articles and citations by ten nations during 2000-2014.

Panels $A$ and $B$ give a semi logarithmic presentation of the publications and citation frequencies of top ten productive countries during 2000-2014. With the most publications and citations, USA claimed the leading status in the HIV/AIDS research field. The growth trends of eight countries (USA, England, France, Italy, Canada, Germany, Spain, and Australia) were similar in their article publications. Two countries (China and South Africa) exhibited significant faster growth rates and became important roles in HIV/AIDS research. In terms of citations, similar growth patterns were observed in eight countries except South Africa and China. The two countries had faster citation growth speeds than other nations. The growth pattern of literatures can reflect the development of science and knowledge. Tague et al. (Tague J, Beheshti J, Rees-Potter L. The law of exponential growth: evidence, implications and forecasts. Library Trends. 1981; 30:125-49) indicated that three possible growth models were available: linear, exponential, and logistic. In the ten year window 2004-2013, linear characteristics were observed in the semi logarithmic presentation of articles and citations growth for most nations, implying the exponential growth of articles 
and citations by these countries.

Panels $\mathrm{C}$ of Figure S1 presents a dynamic picture of the share of HIV/AIDS publications from each country. USA had a stably dominant status in the HIV/AIDS-publications productions, which produced more than two third of total articles among the ten nations during 2000-2014. It had exceeded the aggregate productions of other nine nations. South Africa and China have emerged as new significant contributors in HIV/AIDS research. Since 2012, the two countries have produced the third and fourth largest number of HIC/AIDS articles. In addition, both countries sustained remarkable increases in the share of article publications during 2000-2014. These results are agreed by the annual growth rate and doubling time of article publications during 2004-2013 (Table 1).

With respect to citations in this field (Figure S1, Panel D), USA had the biggest share which was always above 65 percent. Although USA had a predominant impact status, its world share did not significantly change in the 15-year citation time window, which was same as the change of other three nations (Germany, Spain, and Australia). It was observed decreases of citation shares for two nations (France and Italy) and the sustained increases for four nations (England, Canada, China, and South Africa). The fastest increase was observed for South Africa, whose position had improved from ninth (in 2000) to fourth (in 2014) during the 15 years period. As shown in Table 1, China and South Africa exhibited significant higher annual growth rate and shorter doubling time in HIV/AIDS-citations during 2004-2013, which means the HIV/AIDS science impact of both countries becomes stronger and stronger.

Table S1: The number of research institutions (research centers and universities*) and articles.

\begin{tabular}{|c|c|c|c|c|c|}
\hline & \multicolumn{3}{|c|}{ Research Institutions } & \multicolumn{2}{|r|}{ Articles } \\
\hline & Research centers & Universities & Total & Total & Articles per Institution \\
\hline 10 countries & 4,225 & 8,170 & 12,395 & 113,615 & 9.2 \\
\hline USA & 1,287 & 3,280 & 4,567 & 69,535 & 15.2 \\
\hline $\begin{array}{l}\text { England } \\
\text { (UK)** }\end{array}$ & 205 (UK) & 291 (UK) & $\begin{array}{l}496 \\
\text { (UK) }\end{array}$ & 12,441 & 25.1 \\
\hline France & 792 & 566 & 1,358 & 9,719 & 7.2 \\
\hline S Africa & 37 & 130 & 167 & 7,200 & 43.1 \\
\hline Canada & 113 & 329 & 442 & 6,837 & 15.5 \\
\hline Italy & 220 & 236 & 456 & 6,632 & 14.5 \\
\hline China & 211 & 2,481 & 2,692 & 6,462 & 2.4 \\
\hline Germany & 727 & 412 & 1,139 & 6,081 & 5.3 \\
\hline Spain & 530 & 238 & 768 & 5,625 & 7.3 \\
\hline Australia & 103 & 207 & 310 & 4,519 & 14.6 \\
\hline
\end{tabular}

* Data from the Ranking Web of Research Centers and Universities (http://www.webometrics.info/en). There is some overlap in the number of research centers and universities since some research centers are established by universities.

** Research institutions in United Kingdom are included.

Since the number of research institutions in a country may have an impact on its research productivity, Table S2 presents the relevance between the research institutions and publications of the top ten productive countries in HIV/AIDS research. The number of research institutions including research centers and universities of each country were 
retrieved from Ranking Web of Universities (http://www.webometrics.info/). Although there is some overlap in the number of research centers and universities since some research centers are established by universities, we observed that there is no significant connection between the size of research institutions in a country and its research productivity in the specific area of HIV/AIDS.

USA has the most number of universities and research centers. China has the second most number of universities and Germany has the second most number of research centers. The ratio of number of research centers to number of universities is from 1:3 to 3:2 for most countries except China that has the ratio close to $1: 12$. Although China has the second most number of research institutions, the average institutional article publication is the lowest in the ten countries. In contrast to China, South Africa has the least number of research institutions and the highest average institutional publication.

Table S2: 31 core journals of HIV/AIDS research in China

\begin{tabular}{|c|c|c|}
\hline Journals & Records & Fractions ( percent) \\
\hline PLOS ONE & 389 & 5.49 \\
\hline AIDS CARE PSYCHOLOGICAL AND SOCIO MEDICAL ASPECTS OF AIDS HIV & 137 & 1.94 \\
\hline CHINESE MEDICAL JOURNAL & 129 & 1.82 \\
\hline AIDS RESEARCH AND HUMAN RETROVIRUSES & 116 & 1.64 \\
\hline JOURNAL OF VIROLOGY & 106 & 1.50 \\
\hline JAIDS JOURNAL OF ACQUIRED IMMUNE DEFICIENCY SYNDROMES & 103 & 1.46 \\
\hline AIDS & 102 & 1.44 \\
\hline BIOCHEMICAL AND BIOPHYSICAL RESEARCH COMMUNICATIONS & 101 & 1.43 \\
\hline BIOORGANIC MEDICINAL CHEMISTRY LETTERS & 86 & 1.22 \\
\hline AIDS AND BEHAVIOR & 85 & 1.20 \\
\hline BIOORGANIC MEDICINAL CHEMISTRY & 77 & 1.09 \\
\hline SEXUALLY TRANSMITTED DISEASES & 74 & 1.05 \\
\hline INTERNATIONAL JOURNAL OF STD AIDS & 72 & 1.02 \\
\hline JOURNAL OF BIOLOGICAL CHEMISTRY & 57 & 0.81 \\
\hline BMC PUBLIC HEALTH & 57 & 0.81 \\
\hline SEXUALLY TRANSMITTED INFECTIONS & 51 & 0.72 \\
\hline CHINESE JOURNAL OF ORGANIC CHEMISTRY & 51 & 0.72 \\
\hline BMC INFECTIOUS DISEASES & 51 & 0.72 \\
\hline JOURNAL OF NATURAL PRODUCTS & 48 & 0.68 \\
\hline EUROPEAN JOURNAL OF MEDICINAL CHEMISTRY & 47 & 0.66 \\
\hline AIDS PATIENT CARE AND STDS & 47 & 0.66 \\
\hline AIDS EDUCATION AND PREVENTION & 44 & 0.62 \\
\hline VACCINE & 42 & 0.59 \\
\hline VIROLOGY & 40 & 0.57 \\
\hline PEPTIDES & 39 & 0.55 \\
\hline CURRENT MEDICINAL CHEMISTRY & 37 & 0.52 \\
\hline PROGRESS IN BIOCHEMISTRY AND BIOPHYSICS & 36 & 0.51 \\
\hline CURRENT HIV RESEARCH & 36 & 0.51 \\
\hline ACTA CHIMICA SINICA & 36 & 0.51 \\
\hline RETROVIROLOGY & 35 & 0.49 \\
\hline JOURNAL OF VIROLOGICAL METHODS & 35 & 0.49 \\
\hline
\end{tabular}


Table S3: Summary of the 25 references with the highest betweenness centrality scores as shown in Panels A and B of Figure 4.*

\begin{tabular}{|c|c|c|c|c|c|c|}
\hline No. & Node labels & Articles & Frequency & Centrality & Year & Cited References \\
\hline 1 & JIANG SB (1993) & JIANG-1993 & 71 & 0.33 & 1993 & $\begin{array}{l}\text { JIANG SB, 1993, NATURE, V365, P113, DOI } \\
\text { 10.1038/365113A0 }\end{array}$ \\
\hline 2 & WU ZY (2007) & WU-2007 & 170 & 0.32 & 2007 & $\begin{array}{l}\text { WU ZY, 2007, LANCET, V369, P679, DOI } \\
\text { 10.1016/S0140-6736(07)60315-8 }\end{array}$ \\
\hline 3 & ZHANG FJ (2009) & ZHANG-2009 & 72 & 0.32 & 2009 & $\begin{array}{l}\text { ZHANG FJ, 2009, ANN INTERN MED, V151, } \\
\text { P241 }\end{array}$ \\
\hline 4 & RUAN YH (2007) & RUAN-2007 & 58 & 0.32 & 2007 & $\begin{array}{l}\text { RUAN YH, 2007, SEX TRANSM DIS, V34, P592, } \\
\text { DOI 10.1097/01.OLQ.0000253336.64324.EF }\end{array}$ \\
\hline 5 & LU L (2008) & LU-2008 & 85 & 0.31 & 2008 & $\begin{array}{l}\text { LU L, 2008, NATURE, V455, P609, DOI } \\
\text { 10.1038/455609A }\end{array}$ \\
\hline 6 & CHOI KH (2007) & CHOI-2007 & 52 & 0.31 & 2007 & $\begin{array}{l}\text { CHOI KH, 2007, JAIDS-J ACQ IMM DEF, V45, } \\
\text { P77, DOI 10.1097/QAI.0B013E3180415DD7 }\end{array}$ \\
\hline 7 & $\begin{array}{l}\text { STATE COUNCIL } \\
\text { AIDS WORKING } \\
\text { COMMITTEE ... }\end{array}$ & - & 145 & 0.30 & 2007 & $\begin{array}{l}\text { STATE COUNCIL AIDS WORKING COMMITTEE } \\
\text { OFFICE \& UNITED NATIONS THEME GROUP } \\
\text { ON AIDS IN CHINA, 2007, JOINT ASS HIV AIDS } \\
\text { P, V, P }\end{array}$ \\
\hline 8 & LIAO LJ (2010) & LIAO-2010 & 28 & 0.30 & 2010 & $\begin{array}{l}\text { LIAO LJ, 2010, JAIDS-J ACQ IMM DEF, V53, , } \\
\text { DOI 10.1097/QAI.0B013E3181C7D363 }\end{array}$ \\
\hline 9 & CHAN DC (1997) & CHAN-1997 & 146 & 0.29 & 1997 & $\begin{array}{l}\text { CHAN DC, 1997, CELL, V89, P263, DOI } \\
10.1016 / \mathrm{S} 0092-8674(00) 80205-6\end{array}$ \\
\hline 10 & JIANG SB (1999) & JIANG-1999 & 36 & 0.25 & 1999 & $\begin{array}{l}\text { JIANG SB, 1999, J VIROL METHODS, V80, P85, } \\
\text { DOI 10.1016/S0166-0934(99)00041-5 }\end{array}$ \\
\hline 11 & JIANG J (2006) & - & 65 & 0.22 & 2006 & $\begin{array}{l}\text { JIANG J, 2006, SEX TRANSM DIS, V33, P118, } \\
\text { DOI 10.1097/01.OLQ.0000199763.14766.2B }\end{array}$ \\
\hline 12 & CHEN XS (2000) & - & 64 & 0.17 & 2000 & $\begin{array}{l}\text { CHEN XS, 2000, SEX TRANSM DIS, V27, P138, } \\
\text { DOI 10.1097/00007435-200003000-00003 }\end{array}$ \\
\hline 13 & RUAN SM (2008) & - & 40 & 0.15 & 2008 & $\begin{array}{l}\text { RUAN SM, 2008, AIDS BEHAV, V12, P469, DOI } \\
10.1007 / S 10461-008-9361-9\end{array}$ \\
\hline 14 & $\begin{array}{l}\text { GALVIN SR } \\
(2004)\end{array}$ & - & 38 & 0.14 & 2004 & $\begin{array}{l}\text { GALVIN SR, 2004, NAT REV MICROBIOL, V2, } \\
\text { P33, DOI 10.1038/NRMICRO794 }\end{array}$ \\
\hline 15 & CHOI KH (2004) & - & 67 & 0.11 & 2004 & $\begin{array}{l}\text { CHOI KH, 2004, AIDS EDUC PREV, V16, P19, } \\
\text { DOI 10.1521/AEAP.16.1.19.27721 }\end{array}$ \\
\hline 16 & WU ZY (2004) & - & 65 & 0.10 & 2004 & $\begin{array}{l}\text { WU ZY, 2004, AIDS EDUC PREV, V16, P7, DOI } \\
\text { 10.1521/AEAP.16.3.5.7.35521 }\end{array}$ \\
\hline 17 & $\begin{array}{l}\text { ANDERSON AF } \\
(2003)\end{array}$ & - & 56 & 0.10 & 2003 & $\begin{array}{l}\text { ANDERSON AF, 2003, AIDS CARE, V15, P177, } \\
\text { DOI 10.1080/0954012031000068326 }\end{array}$ \\
\hline 18 & CHAN DC (1998) & - & 91 & 0.09 & 1998 & $\begin{array}{l}\text { CHAN DC, 1998, CELL, V93, P681, DOI } \\
10.1016 / \text { S0092-8674(00)81430-0 }\end{array}$ \\
\hline 19 & $\begin{array}{l}\text { MUSTER T } \\
(1993)\end{array}$ & - & 54 & 0.09 & 1993 & MUSTER T, 1993, J VIROL, V67, P6642 \\
\hline 20 & BINLEY J (1997) & - & 10 & 0.09 & 1997 & $\begin{array}{l}\text { BINLEY J, 1997, NATURE, V387, P346, DOI } \\
10.1038 / 387346 \text { A0 }\end{array}$ \\
\hline 21 & $\begin{array}{l}\text { BULLOUGH PA } \\
(1994)\end{array}$ & - & 17 & 0.08 & 1994 & $\begin{array}{l}\text { BULLOUGH PA, 1994, NATURE, V371, P37, } \\
\text { DOI 10.1038/371037A0 }\end{array}$ \\
\hline 22 & CHEN YH (1994) & - & 5 & 0.08 & 1994 & $\begin{array}{l}\text { CHEN YH, 1994, MOL IMMUNOL, V31, P977, } \\
\text { DOI 10.1016/0161-5890(94)90092-2 }\end{array}$ \\
\hline 23 & BEYRER C (2000) & - & 76 & 0.07 & 2000 & $\begin{array}{l}\text { BEYRER C, 2000, AIDS, V14, P75, DOI } \\
10.1097 / 00002030-200001070-00009\end{array}$ \\
\hline 24 & $\begin{array}{l}\text { ECKERT DM } \\
(2001)\end{array}$ & - & 27 & 0.07 & 2001 & $\begin{array}{l}\text { ECKERT DM, 2001, P NATL ACAD SCI USA, V98, } \\
\text { P11187, DOI 10.1073/PNAS.201392898 }\end{array}$ \\
\hline 25 & SU L (2000) & - & 83 & 0.06 & 2000 & $\begin{array}{l}\text { SU L, 2000, J VIROL, V74, P11367, DOI } \\
10.1128 / J V I .74 .23 .11367-11376.2000\end{array}$ \\
\hline
\end{tabular}

*Note: Details of the 25 reference listed in the following List S1. 
List S1: Details of the 25 reference listed in the Table S3.

1. JIANG SB (1993): Jiang SB, Lin K, Strick N, et al. HIV-1 inhibition by a peptide. Nature 1993; 365 : 113

2. WU ZY (2007): Wu ZY, Sullivan SG, Wang Y, et al. Evolution of China's response to HIV/AIDS. Lancet 2007; 369(9562):679-690

Abstract: Four factors have driven China's response to the HIV/AIDS pandemic: (1) existing government structures and networks of relationships; (2) increasing scientific information; (3) external influences that underscored the potential consequences of an HIV/AIDS pandemic and thus accelerated strategic planning; and (4) increasing political commitment at the highest levels. China's response culminated in legislation to control HIV/AIDS-the AIDS Prevention and Control Regulations. Three major initiatives are being scaled up concurrently. First, the government has prioritised interventions to control the epidemic in injection drug users, sex workers, men who have sex with men, and plasma donors. Second, routine HIV testing is being implemented in populations at high risk of infection. Third, the government is providing treatment for infected individuals. These bold programmes have emerged from a process of gradual and prolonged dialogue and collaboration between officials at every level of government, researchers, service providers, policymakers, and politicians, and have led to decisive action.

3. ZHANG FJ (2009): Zhang F, Dou Z, Ma Y, et al. Five-year outcomes of the China National Free Antiretroviral Treatment Program. Ann Intern Med 2009; 151(4): 241-51, W-52.

Abstract: BACKGROUND: China's National Free Antiretroviral Treatment Program began in 2002 and, by August 2008, included more than 52000 patients. OBJECTIVE: To report 5-year outcomes on adult mortality and immunologic treatment failure rates and risk factors. DESIGN: Open cohort analysis of a prospectively collected, observational database. SETTING: China. PATIENTS: All patients in the national treatment database from June 2002 to August 2008. Patients were excluded if they had not started triple therapy or had missing treatment regimen information. INTERVENTION: Antiretroviral therapy according to Chinese national treatment guidelines. MEASUREMENTS: Mortality rate and immunologic treatment failure rate, according to World Health Organization criteria. RESULTS: Of 52191 patients, 48785 were included. Median age was 38 years, 58 percent were men, 53 percent were infected through plasma or blood, and the median baseline CD4 cell count was $0.118 \times 10$ (9) cells/L. Mortality was greatest during the first 3 months of treatment (22.6 deaths per 100 person-years) but decreased to a steady rate of 4 to 5 deaths per 100 person-years after 6 months and maintained this rate over the subsequent 4.5 years. The strongest mortality risk factors were a baseline CD4 cell count less than $0.050 \times 10$ (9) cells/L (adjusted hazard ratio [HR] compared with a count>or=0.200x10(9) cells/L, 3.3 [95 percent $\mathrm{Cl}, 2.9$ to 3.8]) and having 4 to 5 baseline symptom categories (adjusted HR compared with no baseline symptom categories, $3.4[\mathrm{Cl}$, 2.9 to 4.0]). Treatment failure was determined among 31070 patients with 1 or more follow-up CD4 cell counts. Overall, treatment failed for 25 percent of patients (12.0 treatment failures per 100 person-years), with the cumulative treatment failure rate increasing to 50 percent at 5 years. LIMITATION: Immunologic treatment failure does not necessarily correlate well with virologic treatment failure. CONCLUSION: The National Free Antiretroviral Treatment Program reduced mortality among adult patients in China with AIDS to rates similar to those of other low- or middle-income countries. A cumulative immunologic treatment failure rate of 50 percent after 5 years, due to the limited availability of second-line regimens, is of great concern.

4. RUAN YH (2007): Ruan Y, Li D, Li X, et al. Relationship between syphilis and HIV infections among men who have sex with men in Beijing, China. Sex Transm Dis 2007; 34(8): 592-7.

Abstract: BACKGROUND: Little is known about risk of HIV and other STDs among men who have sex with men (MSM) in China. OBJECTIVE: To survey the prevalence and risk factors of HIV and syphilis and evaluate correlation of two infections among MSM in the Chinese capital city. METHODS: A community-based sample of 526 MSM was recruited in 2005 through Internet advertising, community outreach, and peer referring. Interviewer-administered interviews were conducted to collect information on demographics and sexual and other risk behaviors, and blood samples were collected to test for syphilis and HIV infections. RESULTS: Seventeen (3.2 percent) participants were HIV seropositive and 59 (11.2 percent) syphilis seropositive. Sixty-four percent of participants were 
migrants who did not have Beijing residence. Forty percent had $>10$ lifetime male sex partners and 28.8 percent reported having ever had sex with women. Consistent condom use with primary male sex partners ranged from 21 percent to 24 percent, with nonprimary male sex partners from 35 percent to 42 percent, and with female partners around 33 percent. Illicit drug use was not common; only 2.5 percent reported using Ecstasy or ketamine in the past 6 months. Multivariate logistic regression analyses demonstrated that $>10$ lifetime male sex partners were independently associated with seropositivity of both syphilis (OR, 1.9; 95 percent $\mathrm{Cl}, 1.1-3.4$ ) and HIV (OR, 4.3 ; 95 percent $\mathrm{Cl}, 1.4-13.6)$. In addition, HIV infection is significantly associated with syphilis seropositivity (OR, 3.8; 95 percent $\mathrm{Cl}, 1.3-10.8$ ). CONCLUSIONS: High mobility, multiple sexual partners, and high prevalence of unprotected sex behaviors and syphilis infection suggest a potential rapid spread of HIV in Chinese MSM.

5. LU L (2008): Lu L, Jia M, Ma Y, et al. The changing face of HIV in China. Nature 2008; 455(7213): 609-11.

Abstract: HIV has advanced from high-risk groups such as intravenous drug users to some in the general population, according to comprehensive new data from the south of China. What needs to be done to halt its spread?

6. CHOI KH (2007): Choi KH, Ning Z, Gregorich SE, et al. The influence of social and sexual networks in the spread of HIV and syphilis among men who have sex with men in Shanghai, China. J Acquir Immune Defic Syndr 2007; 45(1): 77-84.

Abstract: OBJECTIVES: To analyze characteristics of social and sexual networks and their role as risk factors for HIV and syphilis among men who have sex with men (MSM) in Shanghai, China. DESIGN: A cross-sectional study. METHODS: We recruited 477 participants using a snowball sampling method. We administered a face-to-face questionnaire and provided testing and counseling for HIV and syphilis. RESULTS: The prevalences of HIV and markers for syphilis were 1.47 percent (95 percent confidence interval [Cl]: 0.59 to 3.01 ) and 13.47 percent (95 percent $\mathrm{Cl}: 10.53$ to 16.88 ), respectively. The independent factors associated with lower risk for syphilis infection were having a contact network, overlap of social and sexual networks, meeting other MSM at the gym or through the Internet, having 3 to 5 lifetime male anal sex partners, and having a female steady sex partner. A larger male sexual network size, having been married, being more knowledgeable about HIV, having 6 or more lifetime male anal sex partners, and having steady male or female sex partners were independently associated with having unprotected anal or vaginal intercourse. CONCLUSIONS: Significant associations were found between network characteristics and syphilis infection and unprotected sex. Network-based interventions should be developed to reduce this HIV risk among MSM in China.

7. STATE COUNCIL AIDS WORKING COMMITTEE ... (2007): SCAWCO - State Council AIDS Working Committee Office and UN Theme Group on AIDS in China. A Joint Assessment of HIV/AIDS Prevention, Treatment and Care in China (2007). http://www.chain.net.cn/english//document/20080104163926671004.pdf

Abstract: To achieve the overall objective of the China's Action Plan for Reducing and Preventing the Spread of HIV/AIDS (2006- 2010), the Chinese government strengthened leadership in the prevention and control of the HIV epidemic, developed comprehensive prevention, treatment, care and support initiatives, and monitored on-going progress. This report, prepared by State Council AIDS Working Committee Office and the United Nations Theme Group on AIDS, covers the epidemic situation and the response since 2006, and identifies the ongoing challenges from which recommendations for future guidance are formulated.

8. LIAO LJ (2010): Lu L, Jia M, Ma Y, et al. The changing face of HIV in China. Nature 2008; 455(7213): 609-11.

Abstract: HIV has advanced from high-risk groups such as intravenous drug users to some in the general population, according to comprehensive new data from the south of China. What needs to be done to halt its spread?

9. CHAN DC (1997): Chan DC, Fass D, Berger JM, et al. Core structure of gp41 from the HIV envelope glycoprotein. Cell 1997; 89(2): 263-73. 
Abstract: The envelope glycoprotein of human immunodeficiency virus type 1 (HIV-1) consists of a complex of gp120 and gp41. gp120 determines viral tropism by binding to target-cell receptors, while gp41 mediates fusion between viral and cellular membranes. Previous studies identified an alpha-helical domain within gp41 composed of a trimer of two interacting peptides. The crystal structure of this complex, composed of the peptides N36 and C34, is a six-helical bundle. Three N36 helices form an interior, parallel coiled-coil trimer, while three C34 helices pack in an oblique, antiparallel manner into highly conserved, hydrophobic grooves on the surface of this trimer. This structure shows striking similarity to the low-pH-induced conformation of influenza hemagglutinin and likely represents the core of fusion-active gp41. Avenues for the design/discovery of small-molecule inhibitors of HIV infection are directly suggested by this structure.

10. JIANG SB (1999): Jiang S1, Lin K, Zhang L, Debnath AK. A screening assay for antiviral compounds targeted to the HIV-1 gp41 core structure using a conformation-specific monoclonal antibody. J Virol Methods 1999; 80(1): 85-96.

Abstract: The human immunodeficiency virus type 1 (HIV-1) gp41 plays an important role in membrane fusion between viruses and target cells. The gp41 ectodomain contains two heptad repeat regions adjacent to the $\mathrm{N}$ and $\mathrm{C}$-termini. Peptides derived from these two regions, designated $\mathrm{N}$ and C-peptides, are potent inhibitors of HIV-1 infection and can interact with each other to form a six-stranded coiled-coil, representing the fusogenic core structure of gp41. A monoclonal antibody was generated, designated NC-1, which specifically binds to the complex formed by the $N$ and C-peptides, but not to the individual peptides. An enzyme linked immunosorbent assay (ELISA) was developed using NC-1 for detecting complex formed by $\mathrm{N}$ and C-peptides and for screening of organic compounds for antiviral agents that may interfere with complex formation and inhibit HIV-1 infection. Single point mutations in the C-peptides abolish the complex formation also eliminate their anti-HIV-1 activity. A phenylazo-naphthalene sulfonic acid derivative, designated ADS-J1, was found to inhibit both formation of NC-1 detectable complex and HIV-1-mediated membrane fusion, suggesting that the described ELISA is applicable to rapid screening of libraries of organic compounds for HIV-1 inhibitors targeted to the HIV-1 gp41 core structure.

11. JIANG J (2006): Jiang J, Cao N, Zhang J, et al. High prevalence of sexually transmitted diseases among men who have sex with men in Jiangsu Province, China. Sex Transm Dis 2006; 33(2): 118-23.

Abstract: OBJECTIVE: The objective of this study was to investigate the prevalence of sexually transmitted diseases (STDs), including HIV infection, and sexual risk behaviors among men who have sex with men (MSM) in Jiangsu Province, China. DESIGN: The authors conducted a cross-sectional study. METHODS: From February to July 2003, men who attended 10 participating gay bars in five cities in Jiangsu Province were asked to complete a self-administered questionnaire, including measures of alcohol use and sexual risk behaviors. Blood samples and urethral swabs were taken to examine the presence of STDs, including HIV infection. RESULTS: A total of 144 men were recruited in the study. Forty-six percent of men reported unprotected anal intercourse with their male sexual partners in the past 3 months. No one was found to be HIV-infected, but the prevalence of STDs was high: gonorrhea 2.7 percent, chlamydial infection 8.0 percent, nonchlamydial nongonococcal urethritis 27.7 percent, active syphilis 6.9 percent, hepatitis B virus infection 9.1 percent, herpes simplex virus-2 infection 7.8 percent, and genital warts 13.2 percent. CONCLUSIONS: Given that HIV prevalence among MSM in some other parts of China has been as high as 3 percent, STDs facilitate the transmission of HIV, and high prevalence of STDs and sexual risk behaviors among MSM exist in Jiangsu Province, the potential for the future spread of HIV is of concern, and it is urgent to provide MSMs with STD healthcare services and HIV/AIDS/STD prevention education and intervention.

12. CHEN XS (2000): Chen XS, Gong XD, Liang GJ, Zhang GC. Epidemiologic trends of sexually transmitted diseases in China. Sex Transm Dis 2000; 27(3): 138-42.

Abstract: OBJECTIVE: To describe the current epidemiology of sexually transmitted diseases (STDs), we analyzed the time trends in distribution of reported cases of STDs in China from 1989 to 1998. STUDY DESIGN: Based on the computerized database of the National System of STD Surveillance, a retrospective study of STD cases reported from 1989 to 1998 was carried out. RESULTS: From 1989 to 1998, STD incidence increased significantly in men and women and demonstrated nonlinear growth trends, with the exception of gonorrhea incidence. Between 1990 and 1998, the incidence 
increased more in females (4.20 times) than that in males (3.79 times). Syphilis incidence increased approximately 20 times during this period at an average annual rate of 52.7 percent. Gonorrhea incidence increased 2.6 times during this period at an average annual rate of 11.4 percent, which reached a plateau from 1994 to 1997. Extramarital transmission as source of STD infection has significantly increased from 1995 to 1998. CONCLUSION: The incidence of STDs has continued to increase in China from 1989 to 1998. The epidemic patterns are different from rates in developed counties in which behavior interventions have been successfully implemented, suggesting the need for active behavioral-intervention programs in China.

13. RUAN SM (2008): Ruan S, Yang H, Zhu Y, et al. HIV prevalence and correlates of unprotected anal intercourse among men who have sex with men, Jinan, China. AIDS Behav 2008; 12(3): 469-75.

Abstract: China's HIV epidemic may be shifting towards predominantly sexual transmission and emerging data point to potential increases in HIV prevalence among men who have sex with men (MSM). There is particular need to assess the extent of risk behavior among MSM outside of China's most cosmopolitan cities. We conducted a respondent-driven sampling survey $(N=428)$ to measure HIV seroprevalence and risk behavior among MSM in Jinan, China, the provincial capital of Shandong. HIV prevalence was 0.5 percent (95 percent confidence interval [Cl] 0.1-1.0). Unprotected anal intercourse (UAI) in the last 6 months (reported by 61.4 percent) was associated with buying or selling sex to a man in the last 6 months, syphilis infection, multiple partners in the last month, low HIV knowledge and migrant status. No participant had previously tested for HIV. Risk for HIV transmission is widespread among MSM throughout China; basic prevention programs are urgently needed.

14. GALVIN SR (2004): Galvin SR, Cohen MS. The role of sexually transmitted diseases in HIV transmission. Nat Rev Microbiol 2004; 2: 33-42

Abstract: More than 42 million people worldwide are now infected with HIV, in spite of sustained prevention activities. Although the spread of HIV has been primarily sexual, epidemiological studies have indicated that the efficiency of the spread of HIV is poor, perhaps as infrequently as 1 in every 1,000 episodes of sexual intercourse. However, sexually transmitted diseases (STDs) that cause ulcers or inflammation greatly increase the efficiency of HIV transmission - by increasing both the infectiousness of, and the susceptibility to HIV infection. STDs might be particularly important in the early stages of a localized HIV epidemic, when people with risky sexual behaviour are most likely to become infected. In China, eastern Europe and Russia, there has been a remarkable increase in the incidence of STDs in recent years, and this is reflected in the rapid increase in the spread of HIV in these areas. Targeted STD detection and treatment should have a central role in HIV prevention in these emerging epidemics.

15. CHOI KH (2004): Choi KH, Gibson DR, Han L, et al. High levels of unprotected sex with men and women among men who have sex with men: a potential bridge of HIV transmission in Beijing, China. AIDS Educ Prev 2004; 16(1): 19-30.

Abstract: China is experiencing an emerging HIV epidemic among men who have sex with men (MSM). We investigated sexual risk, risk perception, HIV and condom knowledge, and utilization of prevention services in the first large sample of MSM recruited in Beijing. Four hundred eighty-two MSM were sampled from September 2001 to January 2002. Forty-nine percent of participants reported unprotected anal intercourse with men during the previous 6 months. However, only 15 percent perceived they are at risk for HIV and many had misconceptions about HIV transmission routes and limited knowledge about condoms. Less than one quarter obtained free condoms (24 percent) and condom lubricants (19 percent) in the past 2 years. Multiple logistic regression analysis showed that unprotected insertive anal intercourse was associated with not having a Beijing residence card, having six or more male sexual partners, not having sex with women, having a lifetime history of sexually transmitted diseases (STDs), and having never tested for HIV. Unprotected receptive anal intercourse was independently associated with having six or more male sexual partners, not having sex with women, having a lifetime history of STDs, having never tested for HIV, and having less exposure to HIV prevention services. In addition, 28 percent reported having sex with both men and women during the previous 6 months, and 11 percent had unprotected intercourse with both men and women. This finding suggests that MSM are a potential bridge of HIV transmission to heterosexual women (or vice versa) and that addressing the HIV prevention needs of 
MSM may benefit the wider population.

16. WU ZY (2004): Wu ZY, Rou KM, Cui HX. The HIV/AIDS epidemic in China: history, current strategies and future challenges. AIDS Educ Prev 2004; 16 (3 Suppl A): 7-17.

Abstract: This article reviews the epidemic of HIV infection and AIDS, the Chinese national policy development in response to the epidemic, and disparities between policies and the need for AIDS prevention in China. The HIV epidemic in China has gone through three phases, and it is now at the rapid expansion phase. Since 1988, HIV/AIDS has been addressed from a legal perspective, but in the early stages laws and regulations actually hindered HIV control efforts. Since 1995 efforts have been made to improve policy decisions. Two major strategic plans were issued in 1998 and 2001, with increased government funding for implementation. Although the challenges facing HIV/AIDs control in China are many, the Chinese government is making a stronger commitment for implementing effective AIDS control measures in the country.

17. ANDERSON AF (2003): Anderson AF, Qingsi Z, Hua X, et al. China's floating population and the potential for HIV transmission: a social-behavioural perspective. AIDS Care 2003; 15(2): 177-85.

Abstract: Historical, geo-economic and behavioural perspectives are used in an exploratory analysis of China's migrant or 'floating' population as a factor in the spread of HIV on the mainland. Participants in the interview format survey $(N=506)$ included in-transit individuals in Beijing, and peddlers, restaurant workers, and employment seekers in Shanghai. When viewed in light of various social dynamics, the convenience survey data suggest that elements within this migrant population, as well as their rurally located partners and spouses, may be at increased risk of acquiring the virus. Given the sheer size and broad movement of this population, it is contended that it may well be a 'tipping point' factor in AIDS prevention and control in China.

\section{CHAN DC (1998): Chan DC, Kim PS. HIV Entry and Its Inhibition. Cell 1998; 93(5): 681-684}

19. MUSTER T (1993): Muster T, Steindl F, Purtscher M, et al. A conserved neutralizing epitope on gp41 of human immunodeficiency virus type 1 . J Virol 1993; 67(11): 6642-6647.

Abstract: Vaccination against human immunodeficiency virus type 1 (HIV-1) requires an immunogen which will elicit a protective immunity against viruses that show a high degree of genetic polymorphism. Therefore, the identification of neutralizing epitopes which are shared by many strains would be useful. In previous studies, we established a human monoclonal antibody (2F5) that neutralizes a variety of laboratory strains and clinical isolates of HIV-1. In the present report, we define the amino acid sequence Glu-Leu-Asp-Lys-Trp-Ala (ELDKWA) on the ectodomain of gp41 as the epitope recognized by this antibody. The sequence was found to be conserved in 72 percent of otherwise highly variable HIV-1 isolates. Escape mutants were not detected in cells infected with HIV-1 isolates MN and RF in the presence of antibody 2F5. Since sequence variability of neutralizing epitopes is considered to be a major obstacle to HIV-1 vaccine development, the conserved B-cell epitope described here is a promising candidate for inclusion in a vaccine against AIDS.

20. BINLEY J (1997): Binley J, Moore JP. HIV-cell fusion. The viral mousetrap. Nature 1997; 387(6631):346-8.

Abstract: Comment on Atomic structure of the ectodomain from HIV-1 gp41. [Nature. 1997]

21. BULLOUGH PA (1994): Per A. Bullough PA, Frederick M. Hughson FM, John J. Skehel JJ, et al. Structure of influenza haemagglutinin at the $\mathrm{pH}$ of membrane fusion. Nature 1994; 371: 37-43

Abstract: Low $\mathrm{pH}$ induces a conformational change in the influenza virus haemagglutinin, which then mediates fusion of the viral and host cell membranes. The three-dimensional structure of a fragment of the haemagglutinin in this conformation reveals a major refolding of the secondary and tertiary structure of the molecule. The apolar fusion peptide moves at least $100 \AA$ to one tip of the molecule. At the other end a helical segment unfolds, a subdomain relocates reversing the chain direction, and part of the structure becomes disordered.

22. CHEN YH (1994): Chen YH, Böck G, Vornhagen R, et al. HIV-1 gp41 binding proteins and antibodies to gp41 could inhibit enhancement of human Raji cell MHC class I and II expression by gp41. Mol Immunol 1994; 31(13): 977-82. 
Abstract: Based on our findings, that HIV-1 soluble gp41 could bind to several proteins on the human, T, B and monocyte cells independently of CD4, we examined the effect of HIV-1 soluble gp41 (sgp41;Env amino acids 539-684) on surface expression of MHC I and II, ICAM-1 and CD21 molecules on human Raji cells. Flow cytometry (FACS) analysis demonstrated that sgp41 could selectively enhance MHC class I and II expression on Raji cells, but did not increase expression of other cell surface antigens, such as, CD21 and CD54 (ICAM-1). Soluble gp41 could also enhance MHC class I and II expression on another human B cell line, Bjab. The sgp41-dependent enhancement of the MHC class I and II expression on Raji cells is time- and dose-dependent. The sgp41 enhancement effect on the MHC antigen expression could be inhibited by the sgp41-binding proteins of 45,49 and $62 \mathrm{kD}$ (isolated from Raji-lysate) which could inhibit the spg41-binding to Raji cells. Interestingly, this sgp41-dependent enhancement of the MHC class I and II expression could also be inhibited by two mAbs to HIV-1 gp41, but not by a third mAb binding to a different site on gp41. These results demonstrate that HIV-1 sgp41 can selectively enhance the human Raji cell MHC class I and II antigen expression and this enhancement effect could be inhibited by the sgp41-binding proteins and anti-gp41 antibodies, and suggest that the sgp41-dependent enhancement is mediated by its binding to Raji membrane proteins of 45,49 and 62 kD.

23. BEYRER C (2000): Beyrer C, Razak MH, Lisam K, et al. Overland heroin trafficking routes and HIV-1 spread in south and south-east Asia. AIDS 2000; 14(1): 75-83.

Abstract: OBJECTIVES: Burma produces approximately 60 percent of the world's heroin, Laos is the third leading producer. Recent outbreaks of injecting drug use and HIV-1 in Burma, India, China, and Vietnam have been associated with Burmese and Laotian overland heroin trafficking routes. We analyzed findings from narcotics investigations, molecular epidemiology studies of HIV-1, and epidemiologic and behavioral studies of injecting drug use, to evaluate the roles that the heroin export routes play in the spread of drug use and HIV-1 in south and south-east Asia. METHODS: We reviewed the medical and narcotics literature, the molecular epidemiology of HIV, and did key informant interviews in India, China, and Burma with injecting drug users, drug traffickers, public health staff, and narcotics control personnel. RESULTS: Four recent outbreaks of HIV-1 among injecting drug users appear linked to trafficking routes. Route 1: From Burma's eastern border to China's Yunnan Province, with initial spread of HIV-1 subtype B, and later C. Route 2: Eastern Burma to Yunnan, going north and west, to Xinjiang Province, with $B, C$, and a $B / C$ recombinant subtype. Route 3: Burma and Laos, through northern Vietnam, to China's Guangxi Province, subtype E. Route 4: Western Burma, across the Burma-India border to Manipur, predominant subtype C, and B and E. CONCLUSIONS: Overland heroin export routes have been associated with dual epidemics of injecting drug use and HIV infection in three Asian countries and along four routes. Molecular epidemiology is useful for mapping heroin routes. Single country narcotics and HIV programs are unlikely to succeed unless the regional narcotic-based economy is addressed.

24. ECKERT DM (2001): Eckert DM, Kim PS. Design of potent inhibitors of HIV-1 entry from the gp41 N-peptide region. Proc Natl Acad Sci USA 2001, 98(20): 11187-92.

Abstract: The HIV-1 gp41 envelope glycoprotein promotes fusion of the virus and cell membranes through the formation of a trimer-of-hairpins structure, in which the amino- and carboxyl-terminal regions of the gp41 ectodomain are brought together. Synthetic peptides derived from these two regions (called $\mathrm{N}$ and $\mathrm{C}$ peptides, respectively) inhibit HIV-1 entry. In contrast to $\mathrm{C}$ peptides, which inhibit in the nanomolar range, $\mathrm{N}$ peptides are weak inhibitors with $\mathrm{IC}(50)$ values in the micromolar range. To test the hypothesis that the weak inhibition of $\mathrm{N}$ peptides results from their tendency to aggregate, we have constructed chimeric variants of the N-peptide region of gp41 in which soluble trimeric coiled coils are fused to portions of the gp41 $\mathrm{N}$ peptide. These molecules, which present the $\mathrm{N}$ peptide in a trimeric coiled-coil conformation, are remarkably more potent inhibitors than the $\mathrm{N}$ peptides themselves and likely target the carboxyl-terminal region of the gp41 ectodomain. The best inhibitors described here inhibit HIV-1 entry at nanomolar concentrations.

25. SU L (2000): Su L, Graf M, Zhang Y, et al. Characterization of a virtually full-length human immunodeficiency virus type 1 genome of a prevalent intersubtype (C/B') recombinant strain in China. J Virol 2000; 74(23): 11367-76.

Abstract: A molecular epidemiology study was conducted among more than 100 human immunodeficiency virus type 1 (HIV-1) subtype C seropositive intravenous drug users (IDUs) from 
Liu, P. , Mu, X. \& Xie, H.

China. Genotyping based on the envelope C2V3 coding region revealed the highest homology of the most prevalent virus strains circulating throughout China to subtype $\mathrm{C}$ sequences of Indian origin. Based on these results, a virtually full-length genome representing the most prevalent class of clade C strains circulating throughout China was directly amplified from peripheral blood mononuclear cells of a selected HIV-infected IDU and subcloned. Sequence analysis identified a mosaic structure, suggesting extensive intersubtype recombination events between genomes of the prevalent clade $C$ and ( $\left.\mathrm{B}^{\prime}\right)$-subtype Thai virus strains of that geographic region. Recombinant Identification Program analysis and phylogenetic bootstrapping suggested that there were 10 breakpoints (i) in the gag-pol coding region, (ii) in vpr and at the $3^{\prime}$ end of the vpu gene, and (iii) in the nef open reading frame. (B')-sequences therefore include (i) several insertions in the gag-pol coding region; (ii) 3'-vpr, the complete vpu gene, and the first exons of tat and rev; and (iii) the 5' half of the nef gene. Breakpoints located in the vpr/vpu coding region as well as in the nef gene of $97 \mathrm{cn} 54$ were found at almost identical positions of all subtype $C$ strains isolated from IDUs living in different areas of China, suggesting a common ancestor for the $C / B^{\prime}$ recombinant strains. More than 50 percent of well-defined subtype B-derived cytotoxic T-lymphocyte epitopes within Gag and Pol and 10 percent of the known epitopes in Env were found to exactly match sequences within in this clade $C / B^{\prime}$ chimeric reference strain. These results may substantially facilitate a biological comparison of clade C-derived reference strains as well as the generation of useful reagents supporting vaccine-related efforts in China. 